\title{
Unmeasured anions in children after cardiac surgery
}

\author{
Deirdre Murray, MD, David Grant, MD, N. Murali, MD, and Warwick Butt, MD
}

Objectives: Acidosis caused by increased unmeasured anion levels occurs frequently after cardiac surgery, with uncertain significance. We examined the ability of unmeasured anions and lactate to predict major events after cardiac surgery, in addition to lactate/increased unmeasured anion levels during low cardiac output states.

Methods: In the initial 6 months, all patients admitted after cardiac surgery were enrolled. Arterial samples were taken at $0,4,8,12,24$, and 36 hours postoperatively. The Stewart method was used to calculate excess acid and unmeasured anion levels. Major adverse events were defined as low cardiac output states requiring cardiac massage or mechanical support. In the second 6-month period, data were collected from a further 8 infants during cardiac arrest/extracorporeal membrane oxygenation cannulation.

Results: One hundred thirteen patients were analyzed. Major adverse events occurred in $8(7.1 \%)$ of 113 patients. On admission, metabolic acidosis occurred in 94 of 113 samples: lactate alone $(\mathrm{n}=25)$; mixed lactate and unmeasured anions $(\mathrm{n}=$ $44)$; and unmeasured anions alone $(\mathrm{n}=25)$. All of the patients who experienced major adverse events had unmeasured anion levels of greater than $3 \mathrm{mEq} / \mathrm{L}$ on admission. Initial unmeasured anion levels were significantly higher in those infants with major adverse events $(10.6 \mathrm{mEq} / \mathrm{L}$ [standard deviation, $8.2 \mathrm{mEq} / \mathrm{L}$ ] vs 4.8 $\mathrm{mEq} / \mathrm{L}$ [standard deviation, $6.6 \mathrm{mEq} / \mathrm{L}$ ],$P=.024)$. Lactate levels did not differ between the 2 groups. In the 16 patients sampled during major adverse events, metabolic acidosis occurred in 15 of 16 , with a mean excess acid level of 14.9 $\mathrm{mEq} / \mathrm{L}$ (standard deviation, $8.3 \mathrm{mEq} / \mathrm{L}$ ). Although unmeasured anions made a significant contribution, lactate was the predominant acid.

Conclusions: After cardiac surgery, unmeasured anion levels were significantly higher in those children with major adverse events. The greatest risk of major adverse events was found in children with both increased lactate levels and increased unmeasured anion levels on admission.

From the Paediatric Intensive Care Unit, Royal Children's Hospital, Melbourne, Australia.

Received for publication April 14, 2006; revisions received Aug 2, 2006; accepted for publication Sept 6, 2006.

Address for reprints: Deirdre Murray, MD, Department of Paediatrics, Clinical Investigations Unit, Cork University Hospital, Cork, Ireland (E-mail d.murray@ucc.ie).

J Thorac Cardiovasc Surg 2007;133:235-40

0022-5223/\$32.00

Copyright (C) 2007 by The American Association for Thoracic Surgery

doi:10.1016/j.jtcvs.2006.09.017

A fter cardiac surgery, a predictable decrease in cardiac output occurs. ${ }^{1}$ Predicting which patients will succumb to this low cardiac output state is difficult. The development of metabolic acidosis, and in particular lactic acidosis, has been shown to predict major adverse events (MAEs) after cardiac surgery. ${ }^{2,3}$ Serial lactate levels seem to be a better predictor of outcome than initial lactate levels alone. ${ }^{4}$ Other sources of acidosis are more difficult to measure and are grouped together under the term unmeasured anions (UMAs). Quantification of UMAs can be achieved by using the Stewart method of calculating the strong ion difference. Stewart's biochemical theories have been modified by Figge to allow easy bedside calculation of UMAs by using routine electrolytes and albumin., ${ }^{5,6}$ Using the Stewart method, we have previously shown that UMAs make a significant contribution to acidosis after cardiac surgery and that isolated lactic acidosis occurs infrequently. ${ }^{7}$ The clinical importance of UMAs is still being delineated. A recent report suggests that UMA levels are better than lactate levels at predicting mortality 


$$
\begin{aligned}
& \text { Abbreviations and Acronyms } \\
& \begin{array}{ll}
\text { CI } & =\text { confidence interval } \\
\text { CPB } & =\text { cardiopulmonary bypass } \\
\text { ECMO } & =\text { extracorporeal membrane oxygenation } \\
\text { MAE } & =\text { major adverse event } \\
\text { PICU } & =\text { pediatric intensive care unit } \\
\text { RACHS-1 } & =\text { risk adjustment for congenital surgery-1 } \\
\text { RR } & =\text { relative risk } \\
\text { SD } & =\text { standard deviation } \\
\text { UMA } & =\text { unmeasured anion } \\
\text { XA } & =\text { excess acid }
\end{array}
\end{aligned}
$$

after cardiac surgery. ${ }^{8}$ We wished to examine serial UMA levels and the ability of increased UMA levels to predict MAEs after cardiac surgery. In addition, we measured the contribution of UMAs to acidosis during low cardiac output states after cardiac surgery.

\section{Materials and Methods}

The study took place in a large tertiary referral pediatric intensive care unit (PICU) over a 12-month period. Ethical approval was given by the local hospital ethics committee, and the need for written informed consent was waived because the data were collected as part of routine clinical care.

\section{Post-cardiac Surgery Samples}

In the initial 6 months of the study period, all patients admitted to the PICU after cardiac surgery were enrolled. Both cardiopulmonary bypass $(\mathrm{CPB})$ and non-CPB procedures were included. Incomplete electrolyte data or nonarterial samples were excluded from analysis. Data were collected from routine arterial blood gases and electrolyte analysis at admission to the PICU and at 4, $8,12,24$, and 36 hours postoperatively. Lactate levels were taken from arterial gases and analyzed by using an automated blood gas analyzer (Bayer 865). Electrolytes were measured as standard in our laboratory (Vitros 350 chemistry system; Na, K, and C 1 using potentiometric analysis and $\mathrm{Ca}, \mathrm{Mg}, \mathrm{PO}_{4}$, and albumin using colorimetric analysis).

Our typical bypass prime consisted of $500 \mathrm{~mL}$ of plasmalyte, $100 \mathrm{~mL}$ of $\mathrm{H}_{2} \mathrm{O}, 15 \mathrm{mmol}$ of bicarbonate, $3 \mathrm{mmol}$ of calcium, 20 $\mathrm{mg}$ of heparin, and $100 \mathrm{~mL}$ of $20 \%$ albumin. The circuit is surface coated with 1 unit $(325 \mathrm{~mL})$ of packed red blood cells. Excess prime $(600 \mathrm{~mL})$ was then hemofiltered off before $\mathrm{CP}$

The Stewart method, as modified by Figge, was used to calculate total excess acid (XA) and UMA levels. ${ }^{5,7}$ UMA and XA levels were calculated away from the bedside at a later stage and therefore did not influence patient care. Clinicians were aware of standard acidosis measures: $\mathrm{pH}$, base deficit, and lactate. The equations to determine UMA and XA levels were as follows:

Equation 1: $\mathrm{SID}=\left[\mathrm{HCO}_{3}^{-}\right]+\left[\mathrm{Alb}^{-}\right]+\left[\mathrm{Pi}^{-}\right]$

Equation 2: $\mathrm{XA}=\left(\left[\mathrm{Na}^{+}\right]+\left[\mathrm{K}^{+}\right]+\left[\mathrm{Ca}^{2+}\right]+\left[\mathrm{Mg}^{2+}\right]\right)-$ $\left[\mathrm{Cl}^{-}\right]$corrected - SID

\section{Equation 3: $U M A=X a-$ Lactate}

Equation 4: $\left[\mathrm{Cl}^{-}\right]$corrected $=\left[\mathrm{Cl}^{-}\right]$observed $\times\left(140 /\left[\mathrm{Na}^{+}\right]\right.$ observed) where SID is defined as strong ion difference, $\left[\mathrm{Alb}^{-}\right]$is defined as the negative electrical charge contribution by serum albumin (in grams per liter; $[\mathrm{Alb}] \times([0.123 \times \mathrm{pH}]-0.631)$, and $\left[\mathrm{Pi}^{-}\right]$is defined as the negative charge contributed by serum phosphate (in millimoles per liter; $\left[\mathrm{PO}_{4}\right] \times([0.309 \times \mathrm{pH}] \times-0.469)$.

An increased lactate level was defined as greater than 2 $\mathrm{mmol} / \mathrm{L}$, and an increased UMA level was defined as greater than $3 \mathrm{mEq} / \mathrm{L}$. XA gives a measure of the total excess tissue acid, which consists of lactate and UMAs.

MAEs were defined as low cardiac output states requiring cardiac massage, chest opening, or mechanical support (extracorporeal membrane oxygenation [ECMO] or a left ventricular assist device). Other outcome measures were length of ventilation (in hours) and length of stay (in days).

\section{Low Cardiac Output Samples}

During the initial 6-month period, 3 patients had samples drawn at or immediately before an MAE. Retrospective data from ECMO cannulation records were available for a further 5 patients. During a second 6-month period, a further 8 patients experienced MAEs, and serial arterial samples were collected at $0,4,8$, and 12 hours after cardiac arrest. This provided us with a second data set. Again, the Stewart method was used to calculate XA and UMA levels.

\section{Statistical Analysis}

Means (standard deviations [SDs]) were calculated for UMA and lactate levels at individual time points. Differences between continuous variables were determined by using the Mann-Whitney $U$ test. Relative risks (RRs) and 95\% confidence intervals (CIs) were calculated for MAEs. The Spearman rank sum test was used to assess correlation between linear variables. Analysis of variance between groups was determined where appropriate.

\section{Results}

During the initial 6-month period of recruitment, data were collected from 127 patients admitted to the PICU after cardiac surgery. The mean age was 38.4 months (range, 2 days to 23 years). Four patients were more than 16 years old, but the care of their long-standing congenital cardiac disease continued to be provided in the PICU, and they were therefore included in the analysis.

The surgical procedures were varied, and RACHS-1 categories were as follows: category $1, \mathrm{n}=8$; category $2, \mathrm{n}$ $=50$; category $3, \mathrm{n}=48$; category $4, \mathrm{n}=2$; category $5, \mathrm{n}$ $=0$; and category $6, \mathrm{n}=5$. CPB had been required during surgical intervention in 111 of 127 cases. Mean CPB time was 119.7 minutes (range, 0-373 minutes). Sufficient electrolyte data for analysis were available in 113 patients.

MAEs occurred in $8(6.9 \%)$ of 113 patients. These major events involved loss of cardiac output and need for cardiac massage. In response, 6 of these 8 patients underwent emergency chest reopening, 3 were cannulated for rescue ECMO, and 4 died subsequent to their arrest.

On the initial arterial blood samples taken on admission to the PICU, the mean lactate level was $3.1 \mathrm{mmol} / \mathrm{L}(\mathrm{SD}$, $2.3 \mathrm{mmol} / \mathrm{L}$ ), and the mean UMA level was $5.18 \mathrm{mEq} / \mathrm{L}$ 


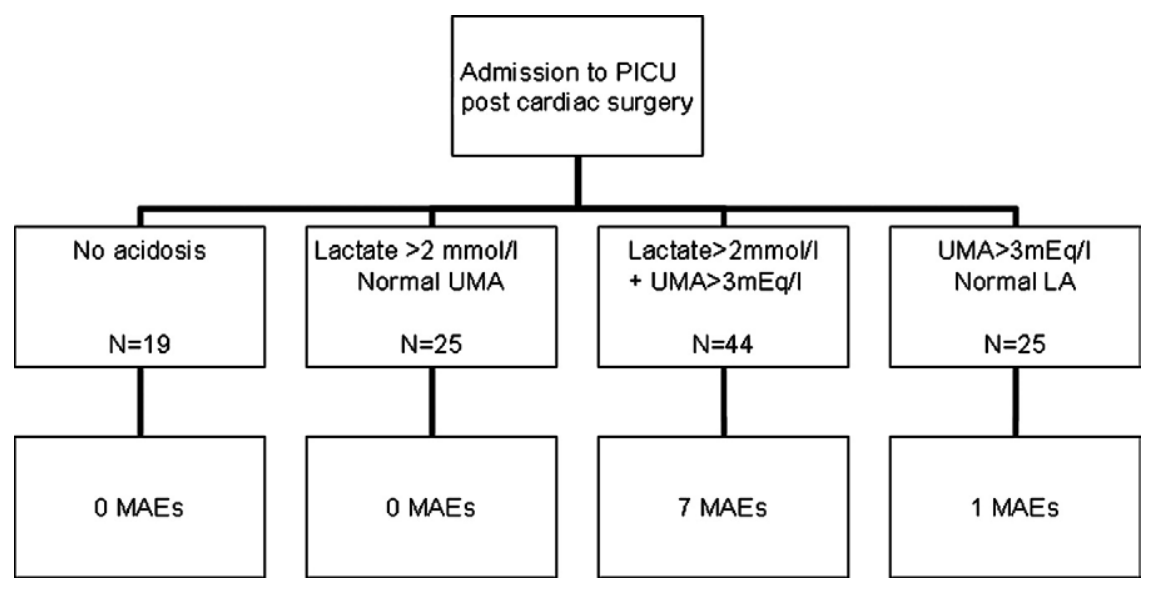

Figure 1. Occurrence of major adverse events (MAEs) in infants arranged according to their acidosis profile on admission to the pediatric intensive care unit (PICU) after cardiac surgery. UMA, Unmeasured anions; $L A$, lactate.

(SD, $6.8 \mathrm{mEq} / \mathrm{L})$. Of the 113 samples, UMA levels were increased $(>3 \mathrm{mEq} / \mathrm{L})$ in 69 patients. All of the patients who later went on to have MAEs had UMA levels of greater than $3 \mathrm{mEq} / \mathrm{L}$ on initial arterial sampling (Figure 1), and therefore RRs compared with patients with UMAs of less than $3 \mathrm{mEq} / \mathrm{L}$ could not be calculated. At a cutoff point of a UMA level of greater than $6 \mathrm{mEq} / \mathrm{L}$, the RR of an MAE was 2.13 (95\% CI, 1.3-3.4). An increased lactate level was less predictive, with an RR for MAE of 1.48 (95\% CI, 1.09-2.01) if the initial lactate level was greater than 2 $\mathrm{mmol} / \mathrm{L}$ and an RR of 1.3 (95\% CI, 0.76-2.21) if the initial lactate level was greater than $6 \mathrm{mmol} / \mathrm{L}$.

On admission, the mean UMA level differed significantly between those infants who would proceed to MAEs
(10.6 mEq/L [SD, 8.2 mEq/L]) and those who would not (4.8 mEq/L [SD, $6.6 \mathrm{mEq} / \mathrm{L}] ; P=.024)$. Initial lactate level did not differ significantly between the 2 groups. The profile of UMA and lactate levels over time (after cardiac surgery) is displayed in Figure 2. A trend for higher UMA levels in those patients with MAEs continued up to 36 hours but was only statistically significant on admission.

Although CPB time correlated with initial lactate level ( $R=0.311, P=.001)$, there was no correlation between UMA levels and CPB time $(R=0.061, P=.52)$.

At all time points, UMA levels did not correlate significantly with length of stay or length of ventilation. Although lactate levels on admission did not correlate with length of stay or length of ventilation, subsequent levels at 6,12 , and
A.

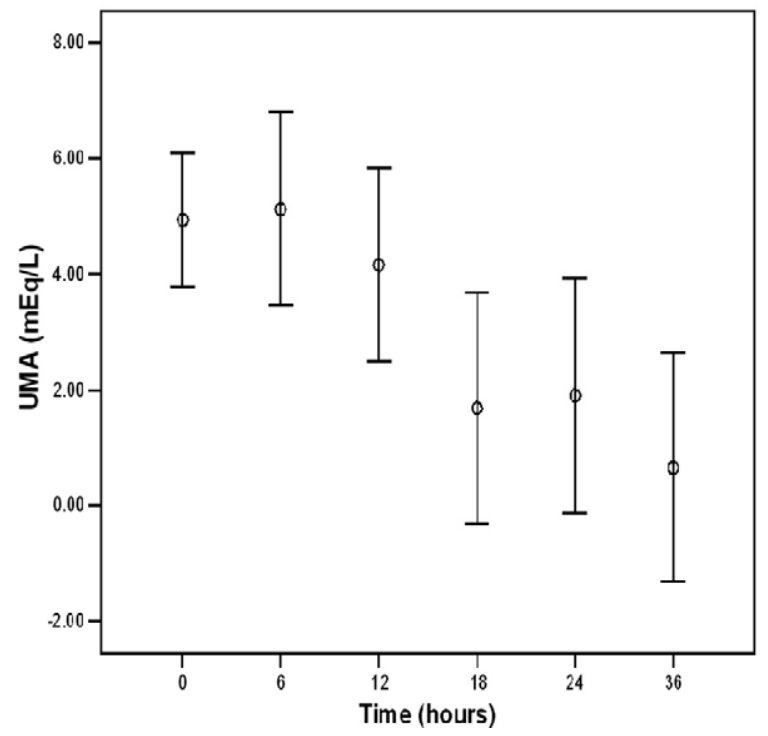

B.

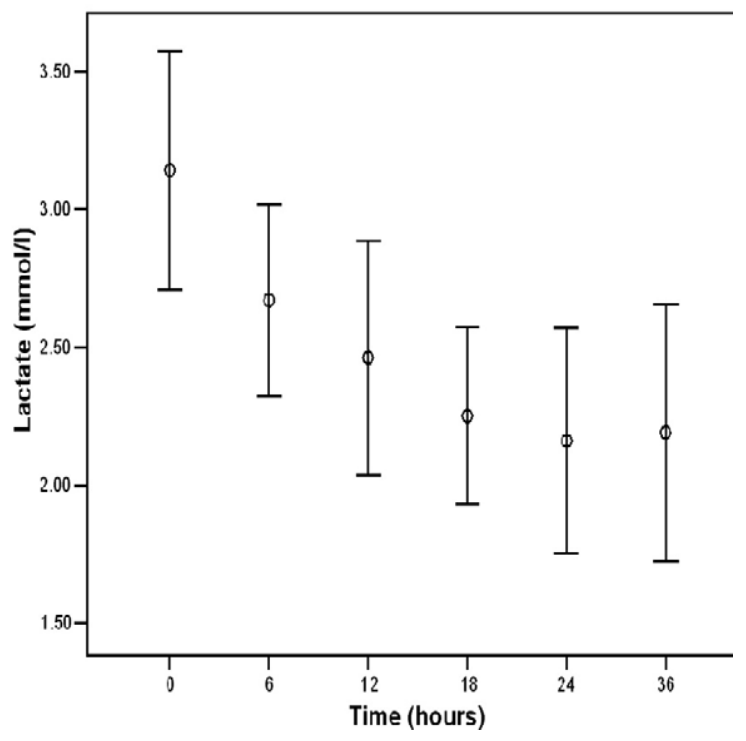

Figure 2. A, Time trend of mean unmeasured anion (UMA) levels after cardiac surgery. B, Time trend of lactate levels after cardiac surgery. Error bars represent $95 \%$ confidence intervals. 
TABLE 1. Demographics, operative details, and outcomes of 16 patients with cardiac arrest or a low cardiac output event requiring mechanical support after cardiac surgery

\begin{tabular}{|c|c|c|c|c|c|c|c|c|c|c|}
\hline Study no. & Age & Sex & Diagnosis & CPB (min) & Postop day & Event & Support & $\operatorname{LOS}(\mathrm{d})$ & LOV (h) & Survival \\
\hline 1 & $3 d$ & $\mathrm{~F}$ & HLHS & 198 & 0 & CA & ECMO & 7 & 160 & No \\
\hline 2 & $3 d$ & $\mathrm{~F}$ & HLHS & 184 & 2 & CA & ECMO & 7 & 157 & No \\
\hline 3 & $10 \mathrm{~d}$ & M & TV dysplasia & 0 & 1 & LCO & ECMO & 2 & 72 & No \\
\hline 4 & $19 \mathrm{~d}$ & $M$ & HRHS & 81 & 0 & CA & LVAD & 12 & 280 & No \\
\hline 5 & $2 d$ & $F$ & HLHS & 201 & 1 & CA & ECMO & 42 & 622 & Yes \\
\hline 6 & $46 \mathrm{~d}$ & $\mathrm{~F}$ & PA & 0 & 2 & CA & ECMO & 24 & 528 & Yes \\
\hline 7 & $1 d$ & M & TAPVD & 132 & 0 & LCO & ECMO & 23 & 540 & No \\
\hline 8 & $9 \mathrm{~d}$ & $M$ & HLHS & 203 & 1 & CA & ECMO & 17 & 408 & No \\
\hline 9 & $2.5 \mathrm{mo}$ & $\mathrm{F}$ & PA, VSD, MAPCAs & 305 & 0 & CA & ECMO & 9.5 & 138 & Yes \\
\hline 10 & 19 mo & $\mathrm{F}$ & Ebstein's anomaly & 0 & 5 & CA & ECMO & 33 & 333 & No \\
\hline 11 & $3 y$ & $\mathrm{~F}$ & Sennings & 282 & 0 & LCO & LVAD & 28 & 220 & Yes \\
\hline 12 & $8 d$ & $\mathrm{~F}$ & HLHS & 299 & 3 & CA & ECMO & 140 & 3309 & No \\
\hline 13 & $17 \mathrm{~d}$ & $\mathrm{~F}$ & MAPCAs & 139 & 1 & CA & ECMO & 2 & 41 & No \\
\hline 14 & $4 d$ & M & PA, VSD, PDA & 127 & 0 & CA & ECMO & 5 & 620 & No \\
\hline 15 & $56 \mathrm{~d}$ & M & Truncus arteriosus & 184 & 0 & CA & & 0.2 & 3 & No \\
\hline 16 & $56 \mathrm{~d}$ & M & $A S D+V S D$ & 117 & 0 & CA & & 10 & 240 & Yes \\
\hline
\end{tabular}

$C P B$, Cardiopulmonary bypass time; Postop day, day after cardiac surgery when arrest/event occurred; LOS, length of stay; LOV, length of ventilation; HLHS, hypoplastic left heart syndrome; $C A$, cardiac arrest; ECMO, extracorporeal membrane oxygenation; $T V$, tricuspid valve; $L C O$, low cardiac output; HRHS, hypoplastic right heart syndrome; $L V A D$, left ventricular assist device; $P A$, pulmonary atresia; TAPVD, total anomalous venous drainage; VSD, ventricular septal defect; MAPCA, major aorto-pulmonary collateral arteries; PDA, patent ductus arteriosus; $A S D$, atrial septal defect.

18 hours after surgical intervention correlated significantly with length of stay $(R=0.223$ and $P=.021$ at 6 hours; $R$ $=0.265$ and $P=.007$ at 12 hours, and $R=0.313$ and $P=$ .007 at 18 hours).

The acidosis profiles in neonates were examined and compared with those of older patients. Although the initial lactate level was higher in neonates than in patients older than 1 month $(4.5 \mathrm{mmol} / \mathrm{L}$ [SD, $2.7 \mathrm{mmol} / \mathrm{L}$ ] vs 2.9 $\mathrm{mmol} / \mathrm{L}[\mathrm{SD}, 2.2 \mathrm{mmol} / \mathrm{L}], P=.003)$, there was no significant difference between UMA levels in the 2 groups $(5.1 \mathrm{mEq} / \mathrm{L}[\mathrm{SD}, 7.4 \mathrm{mEq} / \mathrm{L}]$ vs $5.7 \mathrm{mEq} / \mathrm{L}$ [SD, $6.7 \mathrm{mEq} / \mathrm{L}], P=.943)$.

Others risk factors were examined. There was no correlation between age or weight and MAEs. There were significant correlations between both RACHS- 2 category and CPB time and MAEs $(R=0.184, P=.048$ and $R=0.204$, $P=.03$, respectively). However, our numbers in RACHS-2 categories 5 and 6 are small, and analysis of variance testing showed no significant difference in UMA levels across the differing RACHS-2 categories $(P=.176)$.

During the 6-month study period, 3 patients had arterial blood gas analysis and electrolyte sampling at or immediately before cardiac arrest. We examined these samples and calculated XA and UMA levels for each case. In addition, we retrospectively collected data from 5 infants at the time of cardiac arrest and cannulation for ECMO and prospectively collected data from 8 patients who experienced cardiac arrest or severe low cardiac output states over a further 6 months. In total, this allowed us to examine the acid-base profiles in 16 children at the time of cardiac arrest. Their details and outcomes are displayed in Table 1.

At the time of arrest, 15 of 16 patients had metabolic acidosis (defined as an XA levels of $>5 \mathrm{mEq} / \mathrm{L}$ ), with a mean XA level of $14.9 \mathrm{mEq} / \mathrm{L}$ (SD, $8.3 \mathrm{mEq} / \mathrm{L}$ ). Lactate made up the highest proportion of calculated excess tissue acid. In 5 of 16 patients, the acidosis was almost entirely a lactic acidosis, and in 10 of 16 patients there was a mixed acidosis. In no case was the acidosis entirely caused by UMAs (Figure 3). Patients remained acidotic 12 hours after MAEs, and lactate remained the predominant acid (Figure 4 and Table 2).

During the study period, only 3 patients recruited underwent deep hypothermic circulatory arrest during their surgical procedures. The small number did not allow us to comment on the nature of UMAs in these patients.

\section{Discussion}

We have shown that UMAs make a significant contribution to acidosis immediately after cardiac surgery. This contribution continues up to 36 hours after surgical intervention. Patients who have higher levels of UMAs and lactate postoperatively have an increased risk of MAEs and death. Mean UMA levels were higher in those infants who sustained MAEs throughout the first 36 hours after surgical intervention. Our findings are consistent with those of Durward and colleagues, ${ }^{8}$ who recently reported that UMA levels at 0 and 24 hours postoperatively were superior to lactate levels as a predictor of death. 


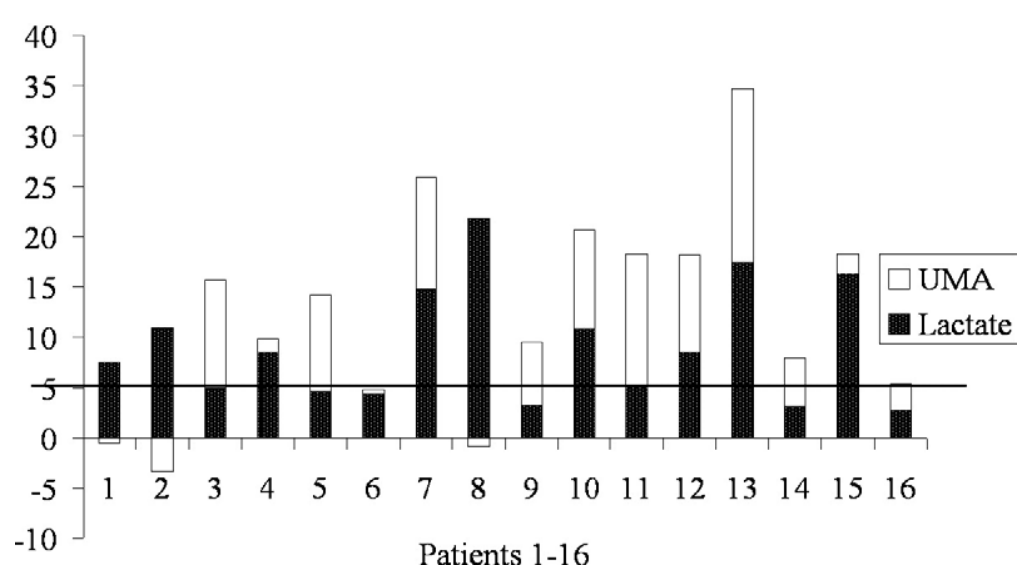

Figure 3. Acidosis at the time of cardiac arrest/low output state in each of 16 patients. Unmeasured anion (UMA) levels are measured in milliequivalent units per liter, and lactate levels are measured in millimoles per liter. The thick black line denotes the upper limit of normal for acidosis (excess acid $=\mathbf{5}$ $\mathrm{mEq} / \mathrm{L})$.

Patients 1-16

Surprisingly, initial lactate levels were not useful in predicting outcome. Subsequent lactate levels from 6 to 18 hours correlated with length of stay but not with MAEs. Previous studies have indicated that serial lactate levels are a better predictor than initial lactate levels alone. ${ }^{4}$ Initial lactate levels might reflect lactate levels of the red blood cell prime solution used during CPB, whereas subsequent lactate levels are a consequence of ongoing oxygen debt. ${ }^{9}$ The importance of UMAs as a morbidity predictor might be due to their occult nature. We are aware of the importance of an increasing lactate level, can measure it easily, and can recognize it as a danger sign. Lactic acidosis is generally reacted to promptly, with escalation in therapy. UMA levels are not routinely calculated, and nonlactic acidosis might not be treated as aggressively. Our study highlights the importance of both lactate and nonlactate acidosis. The majority of MAEs occurred in the group, with increased levels of both lactate and UMAs on admission. This group needs to be recognized as being at increased risk.

However, the majority of patients with increased UMA levels on admission had uneventful postoperative courses. We did not find any UMA level above which the predictive

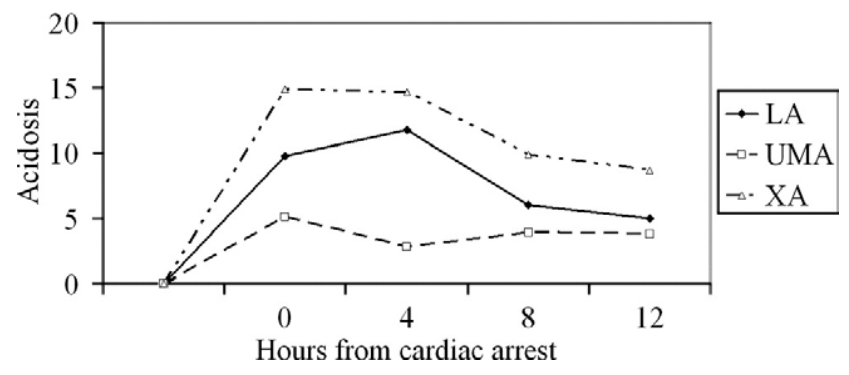

Figure 4. Acidosis at the time of cardiac arrest and 12 hours after arrest. $L A$, Mean arterial lactate level (in millimoles per liter); UMA, mean unmeasured anion level (in milliequivalent units per liter) calculated from arterial sample; $X A$, mean excess acids calculated from arterial sample. ability was clinically useful. Similarly, in general intensive care patients, studies examining the ability of UMA levels and strong ion gap to predict mortality have had mixed results. ${ }^{10-12}$ Perhaps it is too much to ask of a single isolated biochemical measurement to predict the course of a complex, critically ill patient. An increased UMA level should therefore be seen as an indicator of risk and acted on in conjunction with the patient's lactate level and his or her overall clinical condition. Although not yet part of routine clinical care, Stewart's strong ion difference has allowed us to quantify the contribution of differing sources of acidosis in important clinical situations. ${ }^{13-15}$

The origin of UMAs is unknown, and they are most likely a combination of exogenous and endogenous acids. ${ }^{16}$ Although we did not find any correlation with CPB time, it is likely that parts of the CPB prime add exogenous acids, such as citrate and acetone, to the immediate postoperative sample. This will add to the endogenous acid load of ketones, sulfates, and the negative charge of inflammatory proteins. Decreased clearance by the liver and kidney might also decrease the ability to clear UMAs. None of these sources of acid have been quantified in the postoperative cardiac patient. The increase in UMA levels during cardiac arrest cannot be blamed on the bypass prime and gives a clearer reflection of endogenous acid production.

TABLE 2. Acidosis at and after cardiac arrest $(n=16)$

\begin{tabular}{cccc}
\hline $\begin{array}{l}\text { Hours from } \\
\text { cardiac arrest }\end{array}$ & $\begin{array}{c}\text { XA (mEq/L), } \\
\text { mean (SD) }\end{array}$ & $\begin{array}{r}\text { LA (mmol/L), } \\
\text { mean (SD) }\end{array}$ & $\begin{array}{r}\text { UMA (mEq/L), } \\
\text { Mean (SD) }\end{array}$ \\
\hline 0 & $14.9(8.3)$ & $9.8(6.0)$ & $5.1(6.0)$ \\
4 & $14.7(7.6)$ & $11.8(6.8)$ & $2.9(6.8)$ \\
8 & $9.9(6.7)$ & $6.0(4.6)$ & $3.9(4.2)$ \\
12 & $8.7(5.3)$ & $5.0(2.4)$ & $3.8(4.1)$ \\
\hline
\end{tabular}

Data were available from 16 patients at 0 hours, 9 patients at 4 hours, and 8 patients at 8 and 12 hours. $X A$, Excess acids calculated from arterial blood samples; $S D$, standard deviation; $L A$, arterial lactate; UMA, unmeasured anions calculated from arterial samples. 
Importantly, we have shown that during severe low output states, lactate is the predominant source of acid and remains so for the subsequent 12 hours. It is useful to recognize that UMAs make a significant contribution in two thirds of patients, but no patients had isolated UMA acidosis at the time of their MAE. Similarly, a recent study of adults during cardiac arrest found that lactate accounts for only $50 \%$ of metabolic acidosis, with strong ion gap accounting for most of the remainder. ${ }^{17}$

Although all of our patients with MAEs had significant events requiring cardiac massage, mechanical support, or both, we do not routinely use invasive methods of quantifying cardiac output. The availability of reliable continuous cardiac output monitoring would be the ideal and would allow us to accurately track the development of acidosis and its clinical relevance during these crucial postoperative hours.

\section{Conclusions}

Increased UMA levels after cardiac surgery are associated with an increased risk of morbidity and mortality. The greatest risk for MAEs was seen in those patients with both lactate acidosis and increased UMA levels. We have also demonstrated that UMAs make a significant contribution to acidosis during low cardiac output states, albeit secondary to that of lactate.

We acknowledge the help and support of the nursing staff and in particular the ECMO and perfusion staff of the Royal Children's Hospital PICU, without whom it would not have been possible to carry out this study.

\section{References}

1. Wessel DL. Managing low cardiac output syndrome after congenital heart surgery. Crit Care Med. 2001;29(suppl):S220-30.

2. Duke T, Butt W, South M, Karl TR. Early markers of major adverse events in children after cardiac operations. J Thorac Cardiovasc Surg. $1997 ; 114: 1042-52$
3. Hatherhill M, Sajjanhar T, Tibby SM, Champion MP, Anderson D, Marsh MJ. Serum lactate as a predictor of mortality after paediatric cardiac surgery. Arch Dis Child. 1997;77:235-8.

4. Charpie JR, Dekeon MK, Goldberg CS, Mosca RS, Bove EL, Kulilk TJ. Serial blood lactate measurements predict early outcome after neonatal repair or palliation for complex congenital heart disease. J Thorac Cardiovasc Surg. 2000;120:73-80.

5. Fencl V, Jabor A, Kadza A, Figge J. Diagnosis of metabolic acid-base disturbances in critically ill patients. Am J Respir Crit Care Med. 2000;162:2246-51.

6. Stewart PA. Independent and dependent variables of acid base control. Respir Physiol. 1978;33:9-26.

7. Murray DM, Ohhlson V, Fraser J. Defining acidosis in post-operative cardiac patients using Stewart's method of strong ion difference. Pediatr Crit Care Med. 2004;5:240-5.

8. Durward A, Tibby SM, Skellet S, Austin C, Anderson D, Murdoch I The strong ion gap predicts mortality in children following cardiopulmonary bypass surgery. Pediatr Crit Care Med. 2005;6:281-5.

9. Sumpelmann R, Schurholz T, Thorns E, et al. Acid-base, electrolyte and metabolic concentrations in packed red blood cells for major transfusions in infants. Paediatr Anaesth. 2001;11:169-73.

10. Balasubramanyan N, Havens PL, Hoffman GM. Unmeasured anions identified by the Fencl-Stewart method predict mortality better then base excess, anion gap, and lactate in the pediatric intensive care unit. Crit Care Med. 1999;27:1577-81.

11. Haterhill M, Waggie Z, Purves L, et al. Mortality and the nature of metabolic acidosis in children with shock. Intensive Care Med. 2003; 29:286-91

12. Cusack RJ, Rhodes A, Lochhead P, et al. The strong ion gap does not have prognostic value in critically ill patients in a mixed medical/ surgical adult ICU. Intensive Care Med. 2002;28:864-9.

13. Durward A, Skellet S, Mayer A, Taylor D, Tibby SM, Murdoch IA The value of the chloride: sodium ratio in differentiating the aetiology of metabolic acidosis. Intensive Care Med. 2001;27:828-35.

14. Skellet S, Mayer A, Durward A, Tibby SM, Murdoch IA. Chasing the base deficit: hyperchloraemic acidosis following $0.9 \%$ saline fluid resuscitation. Arch Dis Child. 2000;83:514-6.

15. Munoz R, Laussen PC, Palacio G, Zienko L, Piercey G, Wessel D. Changes in whole blood lactate levels during cardiopulmonary bypass for surgery for congenital cardiac disease: an early indicator of morbidity and mortality. J Thorac Cardiovasc Surg. 2000;119:155-62.

16. Kellum JA. Unknown anions and gaps in medical knowledge. Pediatr Crit Care Med. 2005;6:373-4.

17. Makino J, Shigehiko U, Morimatsu H, Bellomo R. A Quantitative analysis of the acidosis of cardiac arrest, a prospective observational study. Crit Care. 2005;9:R357-62. 